\title{
Lápices sin punta - desenho e poesia: imagem da infância na Guerra Civil Espanhola a partir de España, aparta de mí este cáliz, de César Vallejo
}

\section{Carla Damêane P.Souza}

Aluna do Programa de Pós-Graduação em Letras Estudos Literários/UFMG, na linha de pesquisa Literatura e Outros Sistemas Semióticos. Título do projeto "A expressão performativa em España, aparta de mí este cáliz", de César Vallejo.

\section{Resumo}

Este texto busca refletir sobre os discursos alternativos da história através de um diálogo entre o livro España, aparta de mí este cáliz, de César Vallejo, e os desenhos feitos por crianças por ocasião da Guerra Civil Espanhola. Além dessas proposições sobre o texto poético e os desenhos infantis, pretende-se pensar se no Brasil, de alguma forma, as crianças registram suas memórias ou seus traumas pessoais por meio de desenhos.

Palavras-chave: memória, arquivo, poesia, desenho.

No calor das discussões atuais referentes ao grande número de estudos sobre a memória, vale destacar o tópico focado por Jeanne Marie Gagnebin. Em $O$ que significa elaborar o passado? Gagnebin interpreta teóricos que se ocuparam em refletir sobre a relação entre história e memória problemática, no século das guerras e catástrofes, dentre eles, Walter Benjamin e Theodor $W$. Adorno. Na esteira de Adorno, a pesquisadora configura os principais conflitos presentes em relação ao peso do passado referente ao pós-guerra imediato que povoara o mundo de vítimas e algozes, tornando ainda mais intensas as discussões sobre esquecimento, perdão e destruição de lembranças que, na pior das hipóteses, tornaram-se símbolos daquilo que não deve ser esquecido devido a seu grau de crueldade, intolerância e miséria humana.

Gagnebin afirma ser necessário elaborar um passado conjugando lembranças e esquecimentos. Mas, para ela, "a exigência do não 
esquecimento não é um apelo a comemorações solenes; é, muito mais, uma exigência de análise esclarecedora que deveria produzir - e isso é decisivo - instrumentos de análises para melhor esclarecer o presente"(1). Pensando na "pedagogia iluminista", que para Adorno é necessária na luta contra ideologias racistas e fascistas, Gagnebin(2)conclui que, por causa dessa pedagogia esclarecedora e sincera, o passado poderia ser interpretado através de "um trabalho que, certamente lembra dos mortos, por piedade e felicidade, mas também por amor e atenção aos vivos". Sem as amarras de um moralismo rancoroso, a humanidade saberia espelhar-se nas lembranças, por meio da leitura do passado, na construção cotidiana da história presente e vindoura.

Aos setenta anos completos, desde que ocorreu a Guerra Civil Espanhola, a Biblioteca Nacional da Espanha destacou entre suas exposições recentes, "Apesar de todo dibujan: la Guerra Civil vista por los niños", entre os dias 29 de novembro de 2006 e 18 de fevereiro de 2007(3). A curadoria da exposição explicou que dentre 1.127 desenhos infantis tiveram que escolher alguns que representassem as impressões daquelas crianças diante de tal emergência histórica. Eles são, por isso, classificados de acordo com temas a que remetem: "La politización de los niños", "La guerra en Madrid" e "La vida antes de la guerra".

Quisemos começar este texto debruçando-nos justamente sobre o tema de como lidar com as pegadas do passado, principalmente quando ele traz algumas implicações por sua relação com o trágico. Remetendo à Guerra Civil Espanhola, sobre a qual sabemos que houve um verdadeiro massacre de civis e crianças que foram enviadas a outros países ou a orfanatos, ou seja, falamos de crianças que viveram uma realidade bélica e tiveram seus anos de aprendizagem e lazer interrompidos pela guerra.

Ao resgatar esses desenhos, a Biblioteca Nacional da Espanha, embora tenha exposto um número restrito dos tantos trabalhos que possui em seu acervo, permite que esse arquivo venha, senão iluminar, pelo menos indicar-nos um caminho seguro, por meio do qual podemos ver o passado via olhares que estão suspensos em relação à consciência sobre a guerra. São olhares infantis, ingênuos, e sobretudo sinceros, pois estão distantes de consignas ideológicas.

Sobre esses arquivos, os desenhos, eles são documentos históricos que fazem parte das memórias da Guerra Civil Espanhola, dentre outras manifestações que não foram realizadas com o intuito de resistir ao esquecimento, mas que são hoje tratadas por pesquisadores como arquivos. Elas resistem ao tempo e fornecem conhecimento sobre variadas versões e discursos da história em questão. Entre esses 
arquivos da Guerra Civil Espanhola, está o livro España, aparta de mí este cáliz, do poeta peruano César Vallejo, que esteve entre o grupo de intelectuais estrangeiros que se solidarizaram com o que acontecia na Espanha. Vallejo fazia parte do partido comunista peruano, vivia há quinze anos em Paris, de onde pôde acompanhar de perto o apogeu e a queda da República Espanhola, embora tenha falecido em 1938, antes que declarassem oficialmente o fim do conflito.

Diana Taylor, em Encenando a memória cultural: yuyachkaniapresenta distinções referentes aos conceitos de arquivo erepertório, considerando-os como fontes de informações memoralísticas que encenam tempos históricos e trazem à baila debates importantes sobre o passado coletivo que pode interessar a uma ou a outra comunidade. Para a autora, no que se refere à performance, arquivo e repertório não convivem numa relação antagônica, de forma que tanto um como outro são modos de preservação e transmissão de um conhecimento. Em alguns casos, naturalmente, o arquivo serviu como procedimento que enclausurou práticas corporificadas - os exemplos dados por Taylor dizem respeito ao processo de colonização da América Latina, em que o intuito de arquivar para preservar culminou com 0 apagamento de saberes relacionados ao repertório. Mas, em todo caso, Taylor afirma que

seria simples pensar a "performance" como sendo de alguma forma corporificada e liberadora em oposição a um arquivo nãoperformático e não-hegemônico. O arquivo assim como o repertório está repleto de performances verbais - algumas que desaparecem, outras que inventam seu próprio objeto de inquirição(4).

Por se tratar de um arquivo, España, aparta de mí este cáliz, avalia movimentos e sensações reconstituídas a seu modo e presentifica memórias - de quem escreveu e daqueles que ali estão inscritos - e é compreensível entendê-lo como obra de arte que, de acordo com Taylor, em El espetáculo de la memória: trauma, performance política(5), "opera como transmisor de la memória traumática, y a la vez su re-enscenificación", comunicando uma ação passada, e além disso "extrayendo o transformando imágenes culturales comunes de un 'archivo' colectivo".

Até aqui, o que podemos inferir é que a importância do arquivo hoje, no que diz respeito à preservação da memória principalmente em casos onde, além de ser marcada pela relação com o passado histórico, ela consegue ativar dispositivos cuja reflexão acontece no presente - é que ela não pode ser concebida gratuitamente por seus receptores, quer dizer, 0 arquivo não pode ser visto simplesmente como meio de armazenar informações. Em tempos graves, de guerras, ou catástrofes naturais, muitas vezes são esses arquivos que elucidam, para 
nós, discursos que a história oficial não admite. E quando pensamos, por exemplo, no excesso de informações arquivadas que nos trazem encenações de um tempo histórico, devemos entender que cada informação tem algo diferente a nos dizer.

Se, no caso de César Vallejo, seu poemário de guerra constitui-se de todas as características de um testemunho, pela projeção de sua pessoa enquanto aquele que se propôs, como intelectual, fazer valer seu lugar enunciativo diante do campo cultural onde atuava, no caso dos desenhos das crianças podemos considerá-los mais como "restos" que acabaram se transformando em monumento histórico. Pensamos em um monumento que, diferentemente do monumento concreto, relaciona-se com a proporção que esses desenhos, preservados como arquivo, atualmente atingiram, tendo em vista a relação que têm com a memória do tempo da guerra. O monumento, em seu sentido lato, hoje se constitui como imagens registradas instantaneamente pelas crianças e que podem sugerir formas de explicação ou compreensão por parte delas do que acontecia.

Entendemos que esses desenhos representam um conjunto de imagens que buscavam mostrar o reflexo que acontecia sem quaisquer intenções de documentar e interpretar a história, o que não as livrou de documentá-la, pois, uma vez arquivados os desenhos, eles se tornaram um tipo de fonte histórica. Não se trata de fotografias ou filmes, ou mesmo como no caso de España, aparta de mí este cáliz, de uma obra de arte: mesmo assim, são restos de um tempo passado que conseguem encenar a história, tal como um testemunho.

É importante fazer uso de uma consideração de Walter Benjamin, referente à produção e à popularização, no começo do século, dos livros infantis, tal como os brinquedos e todo tipo de artifícios que, inventados pelo adultos, de alguma maneira serviram e servem até hoje para familiarizar a criança com seu mundo. Benjamin diz que, desde o Iluminismo, os pedagogos se esforçam por criar meios de distração para as crianças, posicionando-as diante das imagens de um mundo já pronto, de gente grande, mas que, por outro lado, essas sempre foram seduzidas por algo que - diversamente do que já encontram nos livros e brinquedos - elas mesmas pudessem construir. Daí, a explicação dada por Benjamin com relação ao prazer da criança em freqüentar oficinas de produção:

Elas se sentem atraídas irresistivelmente pelos detritos, onde quer que eles surjam - na construção de casas, na jardinagem, na carpintaria, na confecção de roupas. Nesses detritos, elas reconhecem o resto que o mundo das coisas assume para elas, e só para elas. Com tais detritos, não imitam o mundo dos adultos, mas colocam os restos e os resíduos em uma relação nova e original. Assim, as próprias crianças constroem seu mundo de coisas, um microcosmos no macrocosmos (6). 
o desenho infantil, pergunto-me pensando na consideração de Benjamin, também seria uma forma de representar um "microcosmos no macrocosmos"? Nesses desenhos, havia restos de um tempo passado, e restos porque não foram considerados, naquele presente, como uma representação "macro" - filme, fotografia, relatos, todas as fontes canônicas da história da guerra civil - que regiam os discursos ecoados dos acontecimentos. De que lugar falava essa criança? A partir de que céu acompanhava os bombardeios? Como podemos conferir a esses desenhos, senão por sua qualidade de arquivo, ostatus de monumento e/ou a construção de uma consciência infantil a respeito da guerra?

Daniel Muchnik, em Gallo rojo Gallo negro, los intereses en juego en la Guerra Civil Española, diz que 30.000 crianças espanholas tiveram que deixar o país durante o conflito, sendo que outras 70.000 também deixaram o país, após o fim oficial da guerra e a vitória do fascismo. Fatalmente órfãs, a maioria dessas crianças foram levadas às casas de abrigo ou a antigos seminários emergentemente transformados em colégios, nos vários dos países que as receberam, desde o México até a Rússia. Foram crianças para as quais César Vallejo ofereceu seu poema "España, aparta de mí este cáliz":

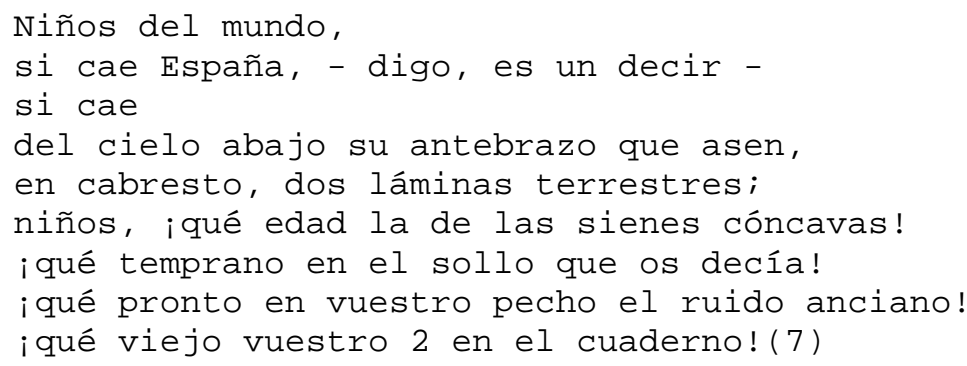

o poema que dá título ao livro de César Vallejo é escrito nos moldes de carta. Ele é cuidadoso, trata-se de um tio, de um professor que vem falar às crianças do mundo. Embora não sejam crianças espanholas, a preocupação, o receio e o aviso, "si cae España" refere-se à Guerra Civil Espanhola, que envolveu um número substancial de brigadistas, oriundos dos quatro cantos do mundo, que foram defender a República Espanhola. O próprio César Vallejo era um poeta peruano que abandeirou-se a favor da resistência antifascista e da defesa da República, a exemplo de outros artistas estrangeiros, como Pablo Neruda, Aléxis Tolstoi, Tristán Tzara.

Diante das crianças do mundo enfermo, resta para Vallejo lamentar em seu poema a sina de cada uma delas, "las de las sienes cóncavas", que envelhecem pela obrigatoriedade de enfrentar tempos difíceis à custa de sua própria educação. Vallejo explica às crianças o que acontece na Espanha: 


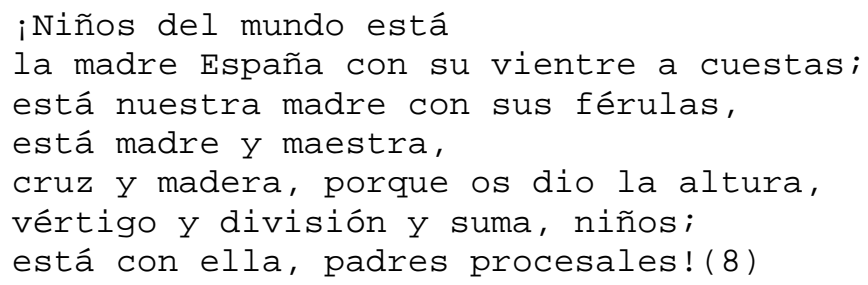

Mais uma vez, o escritor lamenta o efeito de prognósticos, as possíveis conseqüências advindas da queda da Espanha e todo o envelhecimento precoce junto à falta de perspectivas para as crianças que sobrevivessem a essa derrocada, já desiludidos por tê-la experienciado.

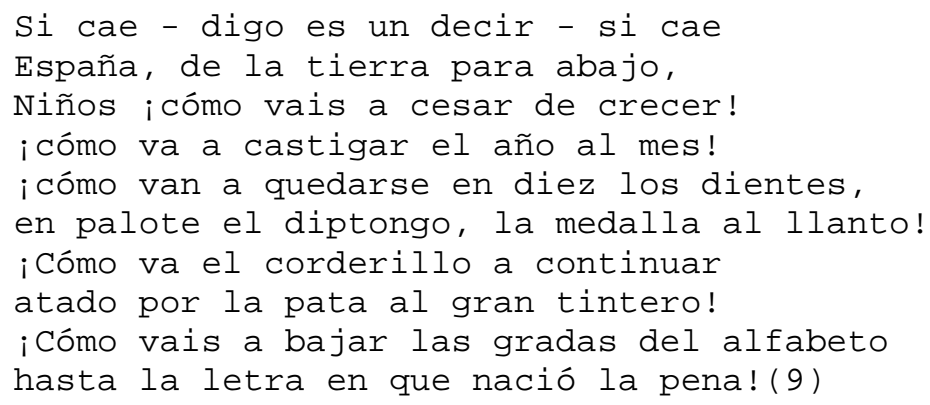

Ao mesmo tempo, o escritor declina sua fala e parece murmurar, como se o medo, como se a ameaça "si cae España" fosse, e era, real. Todo o futuro estaria nas mãos das crianças, filhos de milicianos que sofriam sua tragédia. Eram crianças como Hamlet, falando com uma caveira, tentando apaziguar sua dor pela esperança de um possível triunfo:

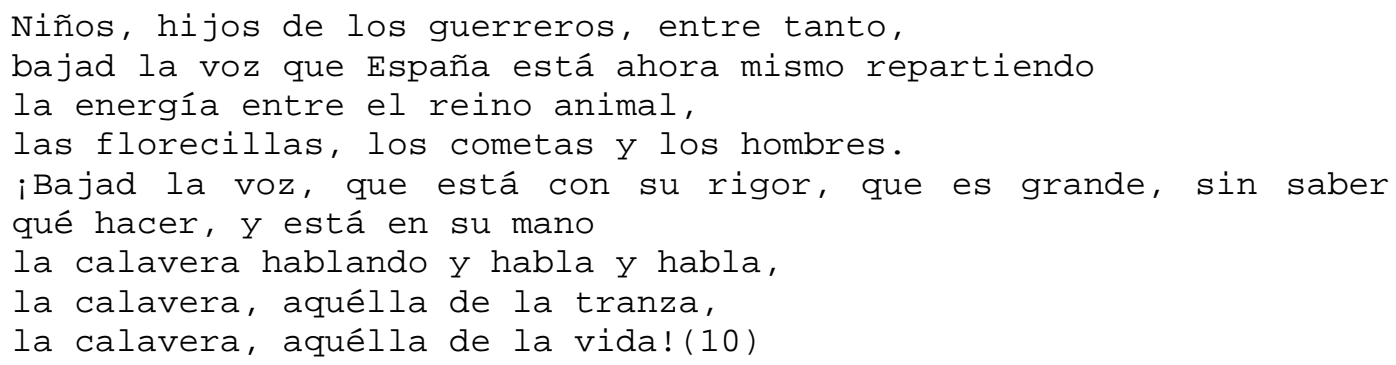

A referência feita a Shakespeare, já havia sido apontada por Júlio Vélez, (11) enquanto nota ao pé de página como proposta de leitura e interpretação da presença da caveira falante. Mas diferente da caveira com que Hamlet fala, a caveira do poema vallejiano, apesar de representar um mau presságio, é uma caveira que presentifica a vida, ou seja, é a morte que fala às crianças vivas, sobreviventes. O poemário de guerra de César Vallejo, em suma, não deixa uma mensagem pessimista diante da guerra, mas uma mensagem positiva, pois é nas crianças que o poeta consegue enxergar uma forma de pôr fim à guerra, de apaziguar a tragédia de ver a Espanha caída e seu lápis sem ponta, como metáfora viva de ruína e perda das ilusões: 


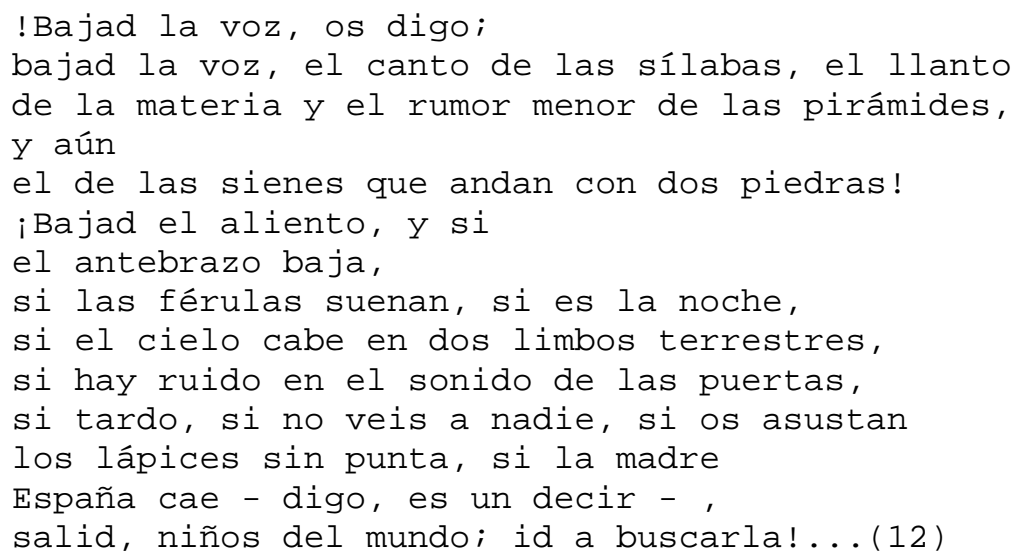

Esse texto vem com uma proposta reflexiva de se pensar a importância dos discursos alternativos da história, como no caso dos desenhos infantis, revelando-os como primordiais na construção da memória da Guerra Civil Espanhola junto ao livro España, aparta de mí este cáliz. Hoje, no Brasil, como poderíamos refletir sobre esse tipo de experiência: o diálogo improvável entre o poema apresentado por nós e os desenhos que estão expostos no site da Biblioteca Nacional de Espanha pensando, por exemplo, nas experiências que nossas crianças passam todos os dias diante de problemas cotidianos? Nesse caso, a Guerra Civil Espanhola representou um trauma para as crianças que a vivenciaram. Em nosso país, de que forma as crianças demonstram seus traumas cotidianos - violência urbana, maus tratos, miséria - e inscrevem suas memórias? Isso acontece por meio de desenhos produzidos por elas nas escolas? No Brasil, há crianças pobres que sequer têm com o que escrever, e apesar da melhoria do ensino público e das condições de vida em geral, muitas ainda não têm acesso à plena educação.

Em geral, artistas de todos os gêneros, da música às artes plásticas, do cinema ao teatro, utilizam meios de dialogar com a posteridade e intervir no campo cultural por meio da catalogação de imagens e descrições de sensações que são reproduzidas em quadros, músicas, filmes, peças de teatro, livros. De que maneira os desenhos infantis, a exemplo dos feitos pelas crianças espanholas, são transformados em monumentos, expostos em museus e bibliotecas? De que forma compreender, de fato, a importância do arquivamento para a atualização de novos discursos sobre a história? E principalmente, seria hoje em dia a cibercultura uma aliada para a projeção dessas formas alternativas de discursos? Como colocar essas formas em diálogo com os discursos hegemônicos ou oficiais?

Mais que questionar, este texto pretendeu demonstrar formas distintas de discursos da história. Uma obra literária escrita na emergência dos eventos - Guerra Civil Espanhola - que nos 
traz imagens bélicas transmitidas por meio do verso, e os desenhos feitos por crianças, também na emergência dos acontecimentos, ajudando a construir uma interpretação mais ampla da história.

A função do arquivo nos dois casos é a de permitir que, distantes há quase um século do que houve na Espanha, possamos nos aproximar do que ela representou, tanto para vallejo, que nesse caso representa os intelectuais, quanto para as crianças, que nesse caso representam os civis - geralmente os que menos têm voz política diante dos discursos de histórias coletivas organizados por uma instituição como o Estado moderno. Há também a função de - concordando com as considerações de Diana Taylor - enriquecer nossos dias de sentido, a partir do reconhecimento da história do outro, pela transmissão performática de um saber.

\section{Resumen}

Este texto propone reflejar acerca de los discursos alternativos de la historia a través de un diálogo entre el libro España, aparta de mí este cáliz, de César Vallejo, con dibujos hechos por niños en la ocasión de la Guerra Civil Española. Además de estas proposiciones sobre el texto poético y los dibujos infantiles, se pretende pensar si en Brasil de alguna manera, los niños inscriben sus memorias o sus traumas personales por medio de dibujos.

Palabras-clave: memoria, archivo, poesia, dibujos.

\section{Anexo}

Desenho de Luis Aparicio Alonso. 10 anos. Valencia. Escuela Hogar Antella. Apresentado no tema "A presença da guerra".

Desenho de Jaime Barrio. 12 anos. Uma Rua de Madri: Cena de um menino antes da guerra. Alicante. Residência Infantil n॰6, San Juan. Encontra-se na sessão "A vida antes da Guerra". 
Desenho de F. Sanz Herranz. Valencia. Colônia escolar madrilenha. Balneario de Bellús. Encontra-se na sessão "Ajuda Humanitária e Evacuação".

Jesús Campos. 13 anos. Valencia. Residência Infantil n²1, Sueca. Apresentada junto ao tema "A ruptura do mundo da infância".

Rafael Cerillo. 13 anos. Bombardeio na fila do leite. Teruel. Colônia escolar Germán de Araujo, Alcañiz. Encontra-se na sessão "A ruptura do mundo da infância".

Evangelina García. 12 anos. Bombardeio em Alicante, Residência Infantil n 23, Biar. Também está junto ao tema "A ruptura do mundo da infância".

Fernando Huertas Banegas. 13 anos. Bombardeio da ambulância vermelha. Valencia. Colônia familiar de Puebla Larga. Encontra-se junto ao tema "A presença da Guerra". 


\section{Notas}

[1] GAGNEBIN, 2006. p. 103.

[2] GAGNEBIN, 2006. p.105.

[3] A exposição até hoje pode ser visitada através do site da Biblioteca Nacional de Espãna, no endereço http://www.bne.es/esp/actividades/apesardetododibujan8.htm. Acesso em 10/08/08. Alguns dos desenhos serão utilizados como ilustração de nosso texto. Estão em anexo ao fim do texto.

[4] TAYLOR, 2002, p.26.

[5] Versão eletrônica de artigo disponível em: http://hemi.nyu.edu/archive/text/hijos2.html. Acesso em: 02/09/08.

[6] BENJAMIN, 1994.p. 238.

[7] VALLEJO, 2000. p.285.

[8] VALLEJO, 2000. p.286.

[9] VALLEJO, 2000. p.286.

[10] VALLEJO, 2000. p.286.

[11] VÉLEZ, 2000.p. 286.

[12] VALLEJO, 2000. p.16.

\section{Referências bibliográficas}

BENJAMIN, Walter. Livros infantis antigos e esquecidos. In:Magia e técnica, arte e politica: ensaios sobre literatura e história da cultura. Tradução de Sérgio Paulo Rouanet. 7. ed. São Paulo: Brasiliense, 1994. p. 235- 248.

BILIOTECA NACIONAL DE ESPAÑA. A Pesar de todo dibujan: La Guerra Civil

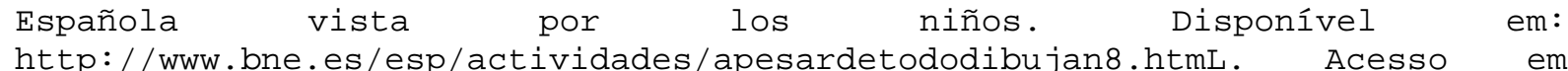
$10 / 08 / 2008$.

GAGNEBIN, Jeanne Marie. O que significa elaborar o Passado? In: Lembrar, escrever, esquecer. São Paulo: Editora 34. 2006.

MUCHNIK, Daniel. Gallo rojo, Gallo negro. Los intereses en juego en la Guerra Civil Española. Buenos Aires: Grupo Editorial Norma, 2004.

TAYLOR, Diana. Encenando a memória cultural social: Yuyachkani. In: ARBEX, Márcia, RAVETTI, Graciela.Performance, exilio, fronteiras: errâncias territoriais e textuais. Belo Horizonte: Departamento de Letras Românicas, Faculdade de Letras/UFMG: Poslit, 2002. p. 12-45.

Hemispheric
El espetáculo de la memória: trauma, performance política.
Institute. http://hemi.nuy.edu/archive/text/hijos2.html. Acesso em: 22/08/2008.

VALlejo, César. Poemas en prosa, poemas humanos, España, aparta de mí este cáliz. Madrid: Cátedra, 2000. 